\title{
BMJ Open Site-specific cancer mortality inequalities by employment and occupational groups: a cohort study among Belgian adults, 2001-2011
}

\author{
Katrien Vanthomme, Laura Van den Borre, Hadewijch Vandenheede, \\ Paulien Hagedoorn, Sylvie Gadeyne
}

To cite: Vanthomme K, Van den Borre L, Vandenheede $\mathrm{H}$, et al. Site-specific cancer mortality inequalities by employment and occupational groups: a cohort study among Belgian adults, 2001-2011. BMJ Open 2017;7:e015216. doi:10.1136/ bmjopen-2016-015216

- Prepublication history and additional material for this paper are available online. To view these files, please visit the journal online (http://dx.doi. org/10.1136/bmjopen-2016015216).

Received 19 November 2016 Revised 16 August 2017 Accepted 23 August 2017
CrossMark

Department of Sociology - Interface Demography, Economic and Social Sciences and Solvay Business School - Vrije Universiteit Brussel, Brussels, Belgium

Correspondence to Katrien Vanthomme; Katrien.Vanthomme@vub.ac.be

\section{ABSTRACT}

Objective This study probes into site-specific cancer mortality inequalities by employment and occupational group among Belgians, adjusted for other indicators of socioeconomic (SE) position.

Design This cohort study is based on record linkage between the Belgian censuses of 1991 and 2001 and register data on emigration and mortality for $01 / 10 / 2001$ to $31 / 12 / 2011$.

Setting Belgium.

Participants The study population contains all Belgians within the economically active age (25-65 years) at the census of 1991 .

Outcome measures Both absolute and relative measures were calculated. First, age-standardised mortality rates have been calculated, directly standardised to the Belgian population. Second, mortality rate ratios were calculated using Poisson's regression, adjusted for education, housing conditions, attained age, region and migrant background.

Results This study highlights inequalities in sitespecific cancer mortality, both related to being employed or not and to the occupational group of the employed population. Unemployed men and women show consistently higher overall and site-specific cancer mortality compared with the employed group. Also within the employed group, inequalities are observed by occupational group. Generally manual workers and service and sales workers have higher site-specific cancer mortality rates compared with white-collar workers and agricultural and fishery workers. These inequalities are manifest for almost all preventable cancer sites, especially those cancer sites related to alcohol and smoking such as cancers of the lung, oesophagus and head and neck. Overall, occupational inequalities were less pronounced among women compared with men.

Conclusions Important SE inequalities in site-specific cancer mortality were observed by employment and occupational group. Ensuring financial security for the unemployed is a key issue in this regard. Future studies could also take a look at other working regimes, for instance temporary employment or part-time employment and their relation to health.

\section{Strengths and limitations of this study}

- This paper probes into socioeconomic (SE) differences in site-specific cancer mortality, using employment and occupational group as measures of socioeconomic position (SEP), accounting for two other SEP indicators (education and housing conditions).

- The findings are based on an exhaustive dataset including the total Belgian population within the economically active age range, which provides very rich information on sociodemographic as well as SE variables and mortality for a follow-up period of 11 years.

- These administrative register data do not contain information on incidence or survival, nor on health behaviours, healthcare use or important aspects of the job (eg, occupational exposures, psychosocial factors).

\section{INTRODUCTION}

In industrialised countries, life expectancy increased during the epidemiological transition, with the most important causes of death (COD) shifting from infectious to chronic diseases such as cancer. ${ }^{1}$ This favourable longevity trend went together with an increase in socioeconomic (SE) health inequalities in general $^{2}{ }^{3}$ and with cancer inequalities in particular. ${ }^{4}$ According to the fundamental cause theory (FCT), inequalities result from the differential distribution of valuable resources that can be used to avoid adverse health outcomes. ${ }^{2}$ This implies that SE inequalities in health will be larger for cancers that are more preventable, either by avoiding risk behaviour or by access to medical interventions, ${ }^{3} 5$ than for less or non-preventable cancers.

SE inequalities in health are one of the most important challenges for public health policies. Therefore, it is crucial to thoroughly document these inequalities. Up till now, most 
studies assessing health inequalities have used only one indicator of socioeconomic position (SEP), most often educational attainment or material wealth. However, detailed research on occupational inequalities in site-specific cancer mortality is scarce ${ }^{67}$ and even non-existent in Belgium. Yet, many studies have shown that, although these SEP indicators are strongly related, they may represent different aspects of SEP ${ }^{8-10}$ Therefore, it is important to establish the role of every single dimension of SEP for every cancer site separately. ${ }^{911} 12$

Hence, this paper probes into SE differences in site-specific cancer mortality, using employment and occupational group as measures of SEP, accounting for the other SEP indicators. By doing so, we aim to estimate the net association between employment and occupational group and site-specific cancer mortality in Belgium, which has not yet been studied. Our first research aim is to examine the magnitude of the association between site-specific cancer mortality and employment group, net of one's educational attainment and housing conditions. The second research aim is to assess whether among the employed group, occupational group is associated with site-specific cancer mortality, again net of education and housing conditions. Based on the FCT, we assume that we will observe inequalities by employment and occupational status, especially for the more preventable cancer sites.

\section{DATA AND METHODS \\ Design and study population}

Data are derived from a record linkage between the Belgian censuses of 1991 and 2001 and register data on emigration and cause-specific mortality for the follow-up period $01 / 10 / 2001$ to $31 / 12 / 2011$. This unique population-based dataset includes information on mortality, emigration, COD, sociodemographic (SD) and SE variables of the total de jure population of Belgium.

All SD and SE variables are extracted from the 2001 census, apart from occupational status for which the 1991 census contains the most recent detailed information. All Belgian individuals who are alive at the 2001 census and who were within the economically active age range (25-65 years) at the census of 1991 are included in the study. For these individuals, we linked information on employment and occupational status, stemming from the 1991 census, irrespective of their employment status at the 2001 census. The study population includes 2333479 Belgian women of whom $49 \%$ are employed and 2231385 Belgian men of whom $80 \%$ are employed. Age is included as a time-varying covariate to account for age changes during the 11-year follow-up period. To do so, individual follow-up time is split into episodes of 5 years attained age groups using Lexis expansions. ${ }^{13}$ Consequently, the age distribution of this population ranges from 35 to 85 years.
Table 1 Cancer sites by ICD-10 classification and level of preventability

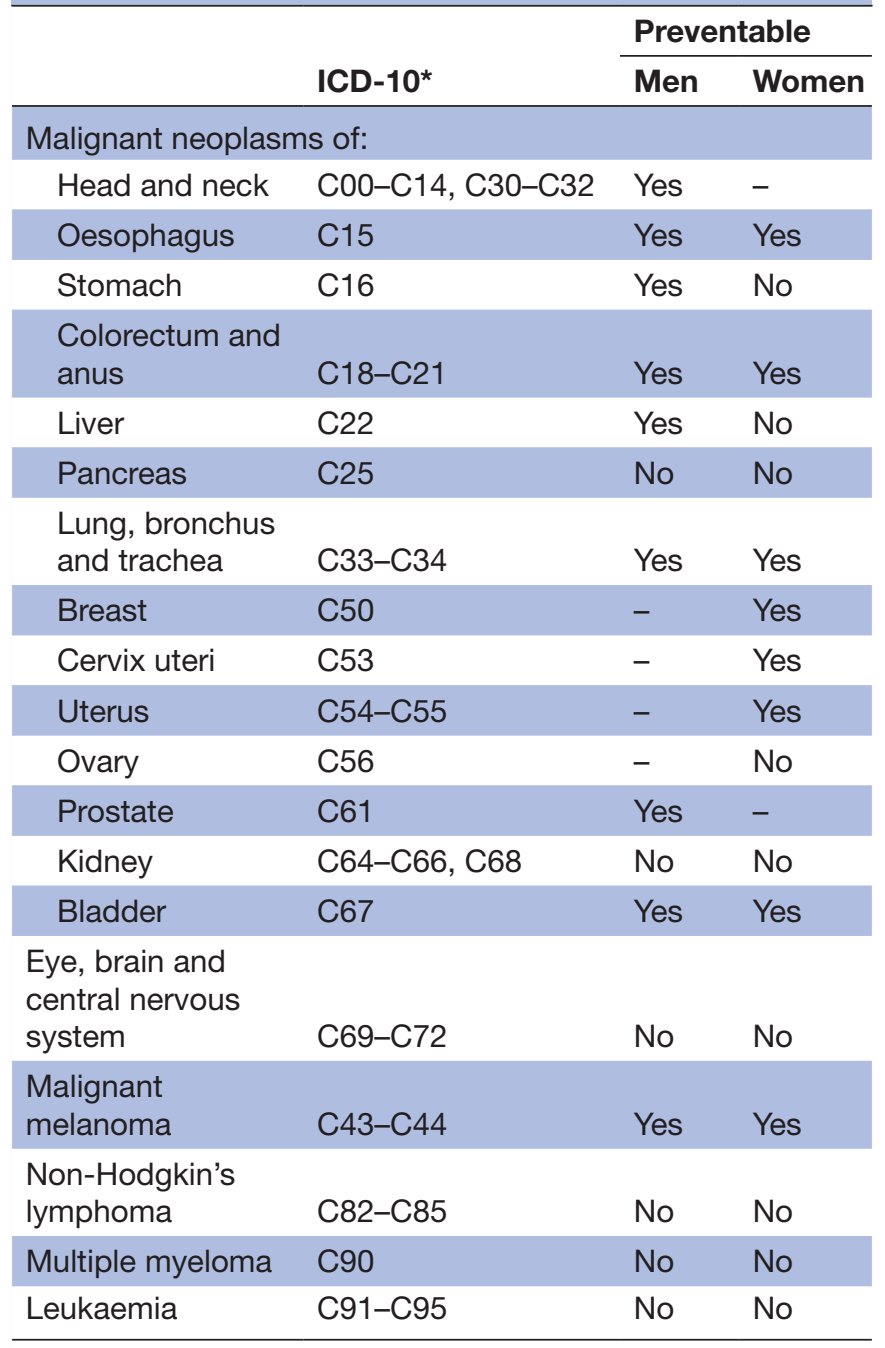

The empty cells are cancer sites not included for either men or women.

* International Classification of Diseases and Related Health Problems - Tenth Revision

\section{Variables}

All cancer sites representing at least $1 \%$ of the total cancer mortality are included. Table 1 gives an overview of these cancer sites, the corresponding ICD-10 codes and the level of preventability. To classify the cancers by level of preventability, we apply the criteria used in Mackenbach's study: ${ }^{14}$ amenability to behavioural change and to medical interventions. Cancer sites are amenable to behavioural change if the combined population attributable fraction of mortality for overweight and obesity, low fruit and vegetable intake, physical inactivity, unsafe sex, smoking and alcohol consumption was larger than 50\% for the European population in the Global Burden of Disease and Risk Factors study. ${ }^{15}$ Cancer sites are considered as amenable to medical interventions, if the 5-year relative survival rate for Belgian women and men in the EUROCARE project was higher than $70 \%$ between 2000 
Table 2 Description of the study population

\begin{tabular}{|c|c|c|c|c|c|}
\hline \multirow[b]{2}{*}{ ISCO* } & \multirow[b]{2}{*}{ Occupational status } & \multicolumn{2}{|l|}{ Men } & \multicolumn{2}{|l|}{ Women } \\
\hline & & Population & Cancer deaths & Population & Cancer deaths \\
\hline & Disabled & 37286 & 2235 & 26905 & 824 \\
\hline & Employed and looking for a job & 121757 & 4418 & 235766 & 2931 \\
\hline & Employed & 1776668 & 34732 & 1146582 & 11943 \\
\hline $3-4$ & Intermediate white-collar workers & 432803 & 8114 & 384478 & 3761 \\
\hline 5 & Service and sales workers & 92369 & 1837 & 167625 & 1670 \\
\hline 6 & Agricultural and fishery workers & 52529 & 1352 & 17303 & 282 \\
\hline $7-8$ & Skilled manual workers & 556418 & 10990 & 87631 & 858 \\
\hline 9 & Unskilled manual workers & 163433 & 3560 & 147887 & 1848 \\
\hline
\end{tabular}

* International Standard Classification of Occupations.

and $2007^{16}$ and/or if effective screening is available in Belgium. ${ }^{17}$

This study probes into cancer mortality inequality among the Belgian population within the economically active age range by using employment and occupational group as a measure of SEP. Both employment and occupational status are derived from the 1991 census and mortality is followed up for the period 2001-2011. Employment status is divided in four categories: employed, unemployed and looking for a job, unemployed and not looking for a job and disabled. Among the employed, we additionally defined their occupational group, based on the International Standard Classification of Occupations (see table 2$):{ }^{18}$ managers and professionals, intermediate white-collar workers, service and sales workers, agricultural and fishery workers, skilled manual workers and unskilled manual workers. We choose the employed as a reference category and among the employed the managers and professionals. These choices have been made because of the size of these groups and because we assume lower cancer mortality for these groups, which facilitates the interpretation.

\section{Statistical analyses}

To obtain a full picture of inequalities in cancer mortality, we calculate both absolute and relative measures, ${ }^{19}$ using complete-case analysis. First, directly age-standardised site-specific mortality rates by employment and occupational group are calculated, using the Belgian population at the 2001 census as standard population. Second, mortality rate ratios (MRR) are calculated using Poisson's regression. We aim to assess the net effect of employment and occupational group on cancer mortality. Therefore, the Poisson's models are adjusted for educational attainment and housing conditions. Educational attainment is categorised using the International Standard Classification of Education: lower secondary education or less (ISCED 0-2, 'low'), higher secondary education (ISCED
3-4, 'mid') and tertiary education (ISCED 5-6, 'high'). Housing conditions is the result of a combination of ownership (tenant or owner) and comfort of the house (low-comfort, mid-comfort and high-comfort), resulting in six categories. ${ }^{20}$ Sensitivity analyses are additionally conducted without adjustment for education and housing conditions. These results are not shown but are available in online supplementary table 1 and 2. Important differences between the crude and net model are mentioned in the discussion section. As there is a strong association in Belgium between mortality and region ${ }^{21}$ as well as migration history, ${ }^{22}$ all Poisson's models are adjusted for region (Flanders, Wallonia and Brussels) and migrant background (native vs non-native). All analyses are stratified by sex and are performed using STATA 13.1.

\section{RESULTS}

\section{Description of the study population}

The study population consists of almost 5 million Belgians within the economically active age range (table 2). Almost four out of five men are employed, whereas in women about one in two has a paid job.

\section{Absolute cancer mortality rates by employment and occupational status}

For almost all preventable cancer sites, men belonging to the employed category have systematically the lowest cancer mortality rates (table 3). Among the employed men, white-collar workers and agricultural and fishery workers have lower cancer mortality rates compared with manual workers (table 4). These results hold true for all preventable cancer sites, except for prostate cancer and malignant melanoma for which no inequality is observed. For the non-preventable cancer sites, less inequalities are observed, as expected based on the FCT. For the non-preventable cancer sites, inequalities generally represent differences between employed versus unemployed. 
Table 3 Absolute site-specific cancer mortality rates (and 95\% Cl) (2001-2011) among the Belgian population within the economically active age range, by employment group in 1991

\begin{tabular}{|c|c|c|c|c|}
\hline Men & Employed & $\begin{array}{l}\text { Unemployed and } \\
\text { looking for a job }\end{array}$ & $\begin{array}{l}\text { Unemployed and not } \\
\text { looking for a job }\end{array}$ & Disabled \\
\hline All cancers & 256.9 (253.8 to 260.0$)$ & 436.4 (423.0 to 449.9$)$ & 380.2 (368.6 to 391.9 ) & 484.3 (462.7 to 506.0$)$ \\
\hline \multicolumn{5}{|l|}{ Preventable cancers } \\
\hline Head and neck & 11.7 (11.2 to 12.3$)$ & 38.6 (34.7 to 42.4$)$ & 24.8 (20.8 to 28.7$)$ & 31.3 (25.0 to 37.6$)$ \\
\hline Oesophagus & $10.3(9.7$ to 10.9$)$ & 20.9 (18.0 to 23.7 ) & 12.8 (10.4 to 15.2$)$ & 15.9 (11.9 to 19.9$)$ \\
\hline Stomach & 8.2 (7.7 to 8.8$)$ & 11.9 (9.7 to 14.2$)$ & 14.5 (12.0 to 17.0$)$ & 17.0 (12.9 to 21.0$)$ \\
\hline Colorectal & 25.8 (24.8 to 26.8 ) & 30.4 (26.8 to 34.0$)$ & 34.3 (30.9 to 37.6$)$ & 33.3 (27.9 to 38.8 ) \\
\hline Liver & 7.8 (7.2 to 8.3$)$ & 12.5 (10.3 to 14.7$)$ & 10.8 (8.6 to 13.0$)$ & 13.5 (9.8 to 17.3$)$ \\
\hline Lung & 88.8 (87.0 to 90.6$)$ & 173.1 (164.6 to 181.7$)$ & 148.8 (141.6 to 156.0$)$ & 195.0 (181.6 to 208.3 ) \\
\hline Prostate & 17.2 (16.3 to 18.1$)$ & 17.3 (14.4 to 20.2 ) & 19.1 (17.6 to 20.6 ) & 27.9 (23.3 to 32.4) \\
\hline Bladder & 8.1 (7.5 to 8.7$)$ & $14.5(12.0$ to 17.1$)$ & 11.8 (10.3 to 13.4$)$ & 19.5 (15.2 to 23.8$)$ \\
\hline Malignant melanoma & 3.0 (2.7 to 3.3 ) & 3.4 (2.2 to 4.5$)$ & 1.9 (1.2 to 2.6$)$ & 3.3 (1.2 to 5.3$)$ \\
\hline \multicolumn{5}{|l|}{ Non-preventable cancers } \\
\hline Pancreas & 13.5 (12.8 to 14.3$)$ & 18.3 (15.5 to 21.1$)$ & 15.4 (13.3 to 17.4$)$ & 21.3 (16.5 to 26.1$)$ \\
\hline Kidney & $7.8(7.2$ to 8.3$)$ & 8.1 (6.3 to 10.0$)$ & $9.0(7.3$ to 10.8$)$ & 12.2 (8.8 to 15.7$)$ \\
\hline Eye, nervous system & 7.3 (6.8 to 7.8$)$ & 6.9 (5.3 to 8.5$)$ & $8.1(6.2$ to 10.1$)$ & $10.4(7.0$ to 13.9$)$ \\
\hline Non-Hodgkin & 6.2 (5.7 to 6.7$)$ & 8.4 (6.5 to 10.3$)$ & 6.9 (5.5 to 8.3$)$ & $10.1(6.7$ to 13.5$)$ \\
\hline Multiple myeloma & 3.8 (3.4 to 4.2 ) & 3.5 (2.3 to 4.6 ) & 4.0 (3.1 to 4.9$)$ & 4.5 (2.4 to 6.6$)$ \\
\hline Leukaemia & 7.6 (7.0 to 8.2 ) & 8.6 (6.6 to 10.6$)$ & 10.1 (8.4 to 11.8$)$ & 9.2 (6.4 to 12.0$)$ \\
\hline Women & Employed & $\begin{array}{l}\text { Unemployed and } \\
\text { looking for a job }\end{array}$ & $\begin{array}{l}\text { Unemployed and not } \\
\text { looking for a job }\end{array}$ & Disabled \\
\hline Cancer deaths & 164.7 (160.0 to 169.4$)$ & 200.2 (181.6 to 218.9 ) & 187.5 (184.8 to 190.3$)$ & 312.4 (286.7 to 338.1$)$ \\
\hline \multicolumn{5}{|l|}{ Preventable cancers } \\
\hline Oesophagus & 3.3 (2.5 to 4.0 ) & 3.0 (2.2 to 3.9 ) & 2.8 (2.5 to 3.1$)$ & 4.7 (2.0 to 7.3 ) \\
\hline Colorectal & 15.4 (14.0 to 16.8$)$ & 16.3 (11.6 to 20.9 ) & 18.5 (17.7 to 19.2$)$ & 35.7 (26.6 to 44.7 ) \\
\hline Lung & $23.9(22.2$ to 25.7$)$ & 40.4 (31.6 to 49.3 ) & 28.7 (27.6 to 29.9$)$ & 51.5 (41.1 to 61.9$)$ \\
\hline Breast & 41.0 (38.8 to 43.1$)$ & 40.7 (33.4 to 47.9 ) & 42.4 (41.0 to 43.8$)$ & 70.8 (58.3 to 83.3) \\
\hline Cervix & 2.8 (2.2 to 3.3$)$ & 7.3 (2.9 to 11.6$)$ & $3.9(3.4$ to 4.4$)$ & $3.8(0.7$ to 6.9$)$ \\
\hline Uterus & 5.6 (4.6 to 6.6$)$ & 5.0 (3.9 to 6.1$)$ & 6.1 (5.6 to 6.5$)$ & 7.4 (3.9 to 10.9$)$ \\
\hline Bladder & 1.6 (1.2 to 2.1$)$ & 2.9 (0.0 to 6.0$)$ & 2.5 (2.2 to 2.8$)$ & 7.6 (3.4 to 11.7$)$ \\
\hline Malignant melanoma & 2.5 (2.0 to 2.9 ) & 3.8 (0.7 to 6.9$)$ & 2.3 (2.0 to 2.6 ) & 1.9 (0.3 to 3.9$)$ \\
\hline \multicolumn{5}{|l|}{ Non-preventable cancers } \\
\hline Stomach & 3.2 (2.6 to 3.9 ) & 4.4 (1.3 to 7.5$)$ & 4.4 (4.0 to 4.8$)$ & 9.8 (4.7 to 14.8$)$ \\
\hline Liver & 2.9 (2.3 to 3.5$)$ & 5.6 (1.3 to 9.9$)$ & 4.6 (4.2 to 5.0$)$ & 6.1 (2.7 to 9.5$)$ \\
\hline Pancreas & $10.4(9.0$ to 11.7$)$ & $8.3(5.0$ to 11.5$)$ & 10.9 (10.3 to 11.5$)$ & 14.5 (9.1 to 19.9$)$ \\
\hline Ovary & 13.4 (12.0 to 14.7$)$ & 9.0 (7.6 to 10.5$)$ & $12.4(11.7$ to 13.1$)$ & 13.2 (8.1 to 18.3$)$ \\
\hline Kidney & 2.8 (2.2 to 3.4$)$ & $5.8(1.4$ to 10.1$)$ & 4.3 (3.9 to 4.7 ) & 6.8 (3.9 to 9.7 ) \\
\hline Eye, nervous system & 5.3 (4.5 to 6.1$)$ & 5.4 (2.3 to 8.5$)$ & 5.7 (5.2 to 6.3$)$ & $11.1(6.2$ to 16.0$)$ \\
\hline Non-Hodgkin & 3.9 (3.1 to 4.7$)$ & 4.6 (1.5 to 7.8$)$ & 4.6 (4.2 to 5.0$)$ & $7.2(2.7$ to 11.8$)$ \\
\hline Multiple myeloma & 2.7 (2.0 to 3.4 ) & 3.2 (0.1 to 6.3$)$ & 3.3 (2.9 to 3.6 ) & $2.1(0.2$ to 4.0$)$ \\
\hline Leukaemia & $5.0(4.1$ to 5.9$)$ & 2.6 (1.8 to 3.4$)$ & 5.3 (4.9 to 5.7$)$ & 8.7 (3.9 to 13.6 ) \\
\hline
\end{tabular}

For women, the absolute inequalities are less pronounced. Generally, mortality from preventable cancer sites is largest for women who are unemployed (table 3). Among the employed women there are no inequalities, except for lung cancer mortality which is somewhat more elevated for service and sales workers and manual workers compared with female managers (table 4). On the other hand, service and sales workers 

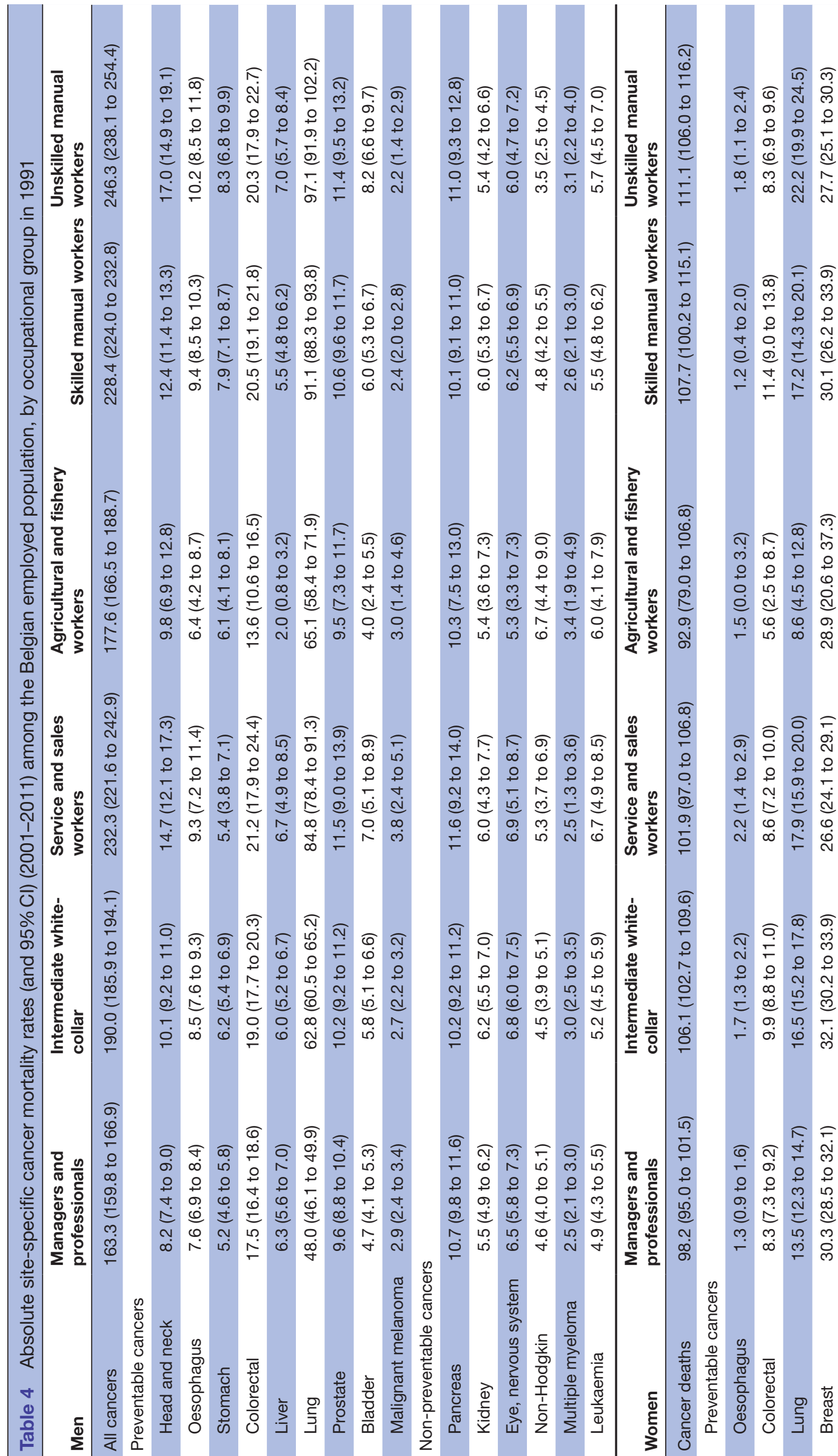

$\underset{\mathrm{m}}{3}$

A 0 व

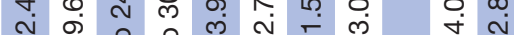
웅융ㅇㅇㅇㅇㅇㅇㅇ Г. ब बें ᄃ் $\infty$ m n

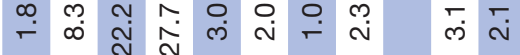
๙ิธ วิ ○ิ N

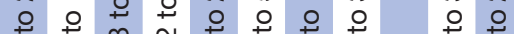
+ อ ר1

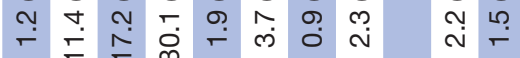

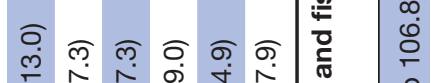

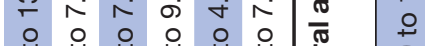

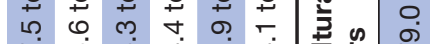
岛

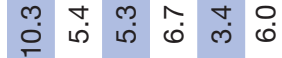
के

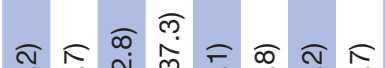
สุ

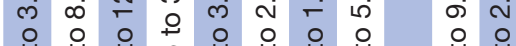
(n อ

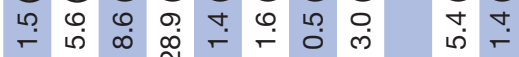

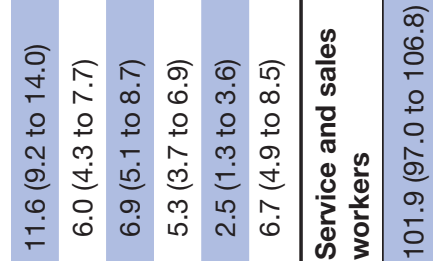

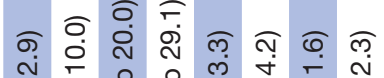

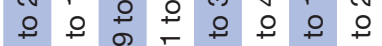
赤 N

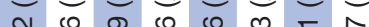

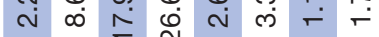

ธิ ต

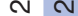
웅 $£=$ $\infty \uparrow$

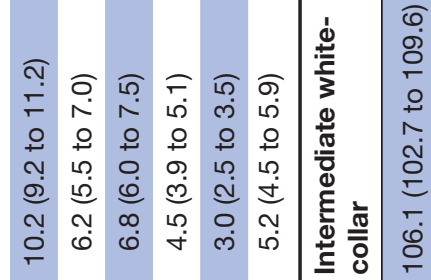
o

สุ

สุ

i $\frac{9}{0}$ o n m

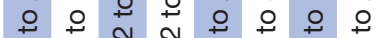

m.

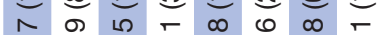

…

우우

?ே.

$\infty$ !

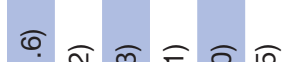

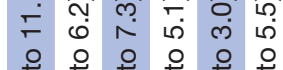

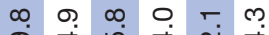

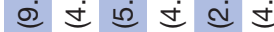

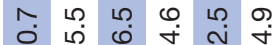
$\frac{0}{0}$
$\frac{0}{0}$
$\frac{0}{\pi}$
0
$\frac{0}{0}$
$\frac{0}{\pi}$

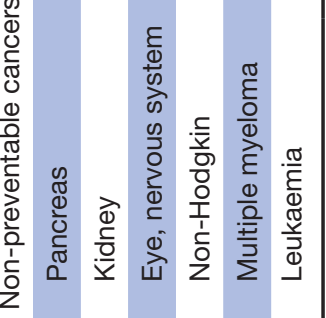

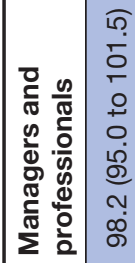

$$
\text { to }
$$

बढ สฺ

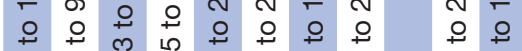
व m

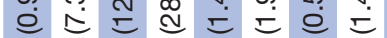

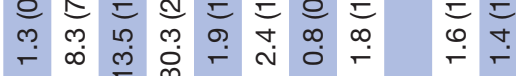

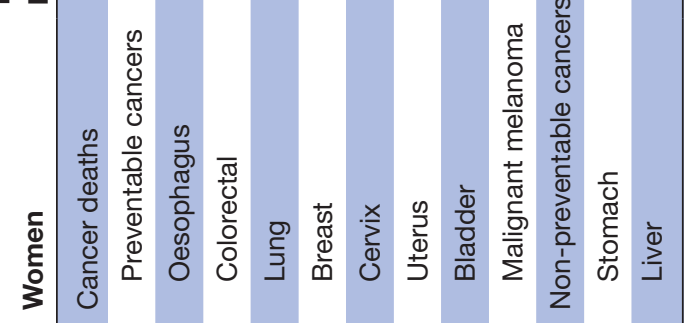

ס

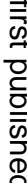

के

$\vec{\circ}$

$\vec{\omega}$

응

$\stackrel{1}{1}$

옹

올

$\vec{O}$

운

$\vec{N}$

Z

$\stackrel{\Phi}{\stackrel{0}{8}}$ 


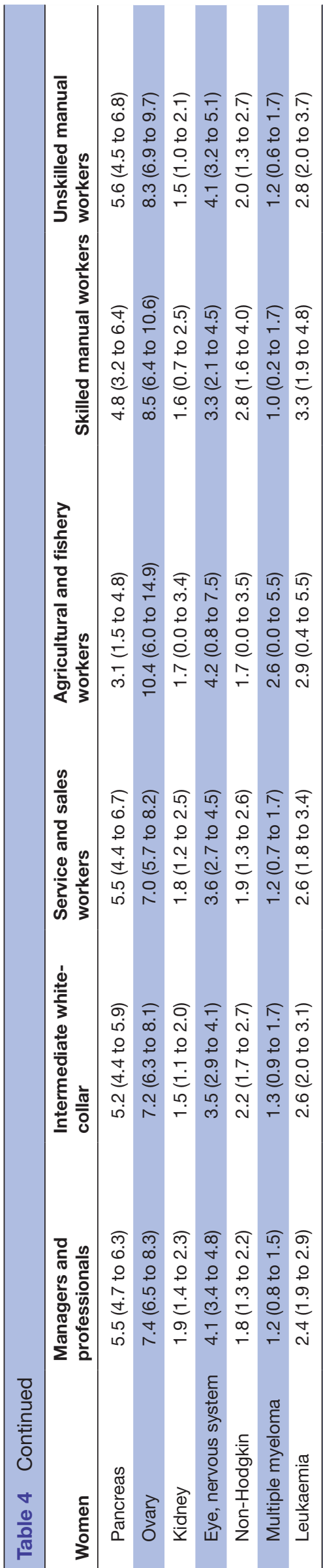

have a lower breast cancer mortality rate compared with intermediate white-collar workers. Neither do we observe an occupational inequality pattern for mortality from non-preventable cancer sites. The only exception is stomach cancer mortality, which is highest among the unskilled manual workers.

\section{Relative cancer mortality inequality by employment and occupational status}

In this paragraph, we present the results of the net relative models, adjusted for education and housing conditions. Unemployed men and women have higher site-specific cancer mortality rates compared with employed people (table 5). This holds true for preventable and non-preventable cancers and are especially observed among the unemployed who are not looking for a job. To illustrate this with an example: unemployed men who are not looking for a job have a three times higher chance of dying from bladder cancer (MRR 3.37; 95\% CI 3.05 to 3.73) compared with employed men. For most cancer sites (mainly the preventable cancers) particularly unemployed men and women who are either not looking for a job or disabled have consistently higher cancer mortality rates compared with employed men and women.

Within the employed population, inequalities by occupation are also observed although more in men than in women (table 6). In men, managers appear to have higher colorectal and liver cancer mortality rates compared with men in other occupations. Furthermore, lower mortality rates in favour of manual workers are observed for several non-preventable cancer sites, among others cancer of the pancreas and kidney. Compared with male managers, skilled manual workers have a $7 \%$ higher lung cancer mortality rate. Another interesting observation is the mortality pattern of the agricultural and fishery workers. Compared with managers, they tend to die less from preventable cancers such as head and neck and oesophageal cancers. Their liver cancer mortality rate is even $76 \%$ lower compared with managers (MRR 0.24; $95 \%$ CI 0.15 to 0.39 ). In contrast, agricultural and fishery workers show higher mortality from some non-preventable cancer sites such as leukaemia and multiple myeloma. Female manual workers and service and sales workers have about $25 \%$ lower breast cancer mortality rates compared with female managers.

\section{DISCUSSION AND CONCLUSION Methodological issues}

The findings are based on a high-quality and exhaustive dataset including the total Belgian population within the economically active age range. A numerator-denominator bias was eliminated through record linkage between census and register data. This dataset provides very rich information on SD as well as SE variables and mortality for a follow-up period of 11 years. This enables us to give precise estimates of site-specific cancer mortality inequalities at the individual level. However, these register data 
Table 5 Net relative site-specific cancer mortality inequality (mortality rate ratios and 95\% Cl) (2001-2011) among the Belgian population within the economically active age range, by employment group in 1991

\begin{tabular}{|c|c|c|c|c|c|c|c|}
\hline \multirow{2}{*}{$\begin{array}{l}\text { Men } \\
\text { All cancers }\end{array}$} & \multirow{2}{*}{$\begin{array}{l}\text { Employed } \\
1.00\end{array}$} & \multicolumn{2}{|c|}{$\begin{array}{l}\text { Unemployed and looking for a } \\
\text { job }\end{array}$} & \multicolumn{2}{|c|}{$\begin{array}{l}\text { Unemployed and not looking for a } \\
\text { job }\end{array}$} & \multicolumn{2}{|c|}{ Disabled } \\
\hline & & 1.60 & 1.55 to 1.65 & 2.74 & 2.69 to 2.80 & 2.28 & 2.19 to 2.37 \\
\hline Head and neck & 1.00 & 2.33 & 2.10 to 2.59 & 2.73 & 2.46 to 3.02 & 2.18 & 1.80 to 2.65 \\
\hline Oesophagus & 1.00 & 2.09 & 1.83 to 2.38 & 2.36 & 2.12 to 2.62 & 1.98 & 1.59 to 2.48 \\
\hline Liver & 1.00 & 1.49 & 1.25 to 1.76 & 2.31 & 2.06 to 2.60 & 2.29 & 1.82 to 2.88 \\
\hline Lung & 1.00 & 1.71 & 1.63 to 1.79 & 2.86 & 2.77 to 2.95 & 2.52 & 2.37 to 2.69 \\
\hline Prostate & 1.00 & 1.17 & 1.01 to 1.35 & 2.78 & 2.59 to 2.99 & 2.30 & 1.96 to 2.70 \\
\hline Bladder & 1.00 & 1.91 & 1.62 to 2.25 & 3.37 & 3.05 to 3.73 & 2.65 & 2.13 to 3.29 \\
\hline Kidney & 1.00 & 1.18 & 0.97 to 1.45 & 2.39 & 2.14 to 2.68 & 2.52 & 2.01 to 3.16 \\
\hline Eye, nervous system & 1.00 & 0.94 & 0.75 to 1.17 & 2.14 & 1.88 to 2.44 & 2.15 & 1.64 to 2.82 \\
\hline Non-Hodgkin & 1.00 & 1.35 & 1.09 to 1.66 & 2.42 & 2.13 to 2.75 & 1.79 & 1.33 to 2.43 \\
\hline Multiple myeloma & 1.00 & 1.25 & 0.93 to 1.68 & 2.86 & 2.46 to 3.32 & 1.48 & 0.97 to 2.25 \\
\hline Leukaemia & 1.00 & 1.05 & 0.84 to 1.31 & 2.73 & 2.44 to 3.06 & 1.72 & 1.30 to 2.28 \\
\hline Women & Employed & $\begin{array}{l}\text { Uner } \\
\text { job }\end{array}$ & looking for a & $\begin{array}{l}\text { Unen } \\
\text { job }\end{array}$ & d not looking for a & Disal & \\
\hline Cancer deaths & 1.00 & 1.11 & 1.07 to 1.15 & 1.74 & 1.71 to 1.78 & 1.96 & 1.83 to 2.09 \\
\hline \multicolumn{8}{|l|}{ Preventable cancers } \\
\hline Oesophagus & 1.00 & 1.35 & 1.04 to 1.75 & 1.67 & 1.40 to 1.99 & 1.94 & 1.15 to 3.26 \\
\hline Malignant melanoma & 1.00 & 1.02 & 0.79 to 1.32 & 1.35 & 1.14 to 1.59 & 1.09 & 0.54 to 2.21 \\
\hline \multicolumn{8}{|l|}{ Non-preventable cancers } \\
\hline Stomach & 1.00 & 1.03 & 0.81 to 1.31 & 1.70 & 1.48 to 1.96 & 2.26 & 1.50 to 3.40 \\
\hline Liver & 1.00 & 1.10 & 0.84 to 1.44 & 2.31 & 1.99 to 2.68 & 1.63 & 0.98 to 2.70 \\
\hline Pancreas & 1.00 & 0.94 & 0.80 to 1.11 & 1.76 & 1.61 to 1.92 & 1.65 & 1.23 to 2.22 \\
\hline Ovary & 1.00 & 0.99 & 0.86 to 1.14 & 1.56 & 1.44 to 1.69 & 1.13 & 0.82 to 1.56 \\
\hline Kidney & 1.00 & 1.21 & 0.93 to 1.57 & 2.04 & 1.76 to 2.35 & 3.33 & 2.28 to 4.87 \\
\hline Eye, nervous system & 1.00 & 0.79 & 0.64 to 0.98 & 1.61 & 1.43 to 1.80 & 1.39 & 0.89 to 2.18 \\
\hline Non-Hodgkin & 1.00 & 0.99 & 0.76 to 1.29 & 1.96 & 1.70 to 2.25 & 1.54 & 0.95 to 2.52 \\
\hline Multiple myeloma & 1.00 & 0.93 & 0.65 to 1.34 & 2.33 & 1.96 to 2.77 & 1.32 & 0.65 to 2.69 \\
\hline Leukaemia & 1.00 & 0.75 & 0.57 to 0.97 & 1.66 & 1.46 to 1.88 & 1.35 & 0.85 to 2.15 \\
\hline
\end{tabular}

Reference category is employed.

All analyses are adjusted for current age, region, migrant background, educational attainment and housing conditions.

do not contain information on incidence or survival, nor on health behaviours, healthcare use or important aspects of the job (eg, occupational exposures, psychosocial factors), which are all likely to be associated with cancer outcomes. ${ }^{23}$ Therefore, it is difficult to make solid conclusions on the relative importance of all these factors to explain the observed SE inequalities in cancer mortality. ${ }^{23} 24$

We included the total Belgian population that belonged to the economically active age group (25-65 years) at the 


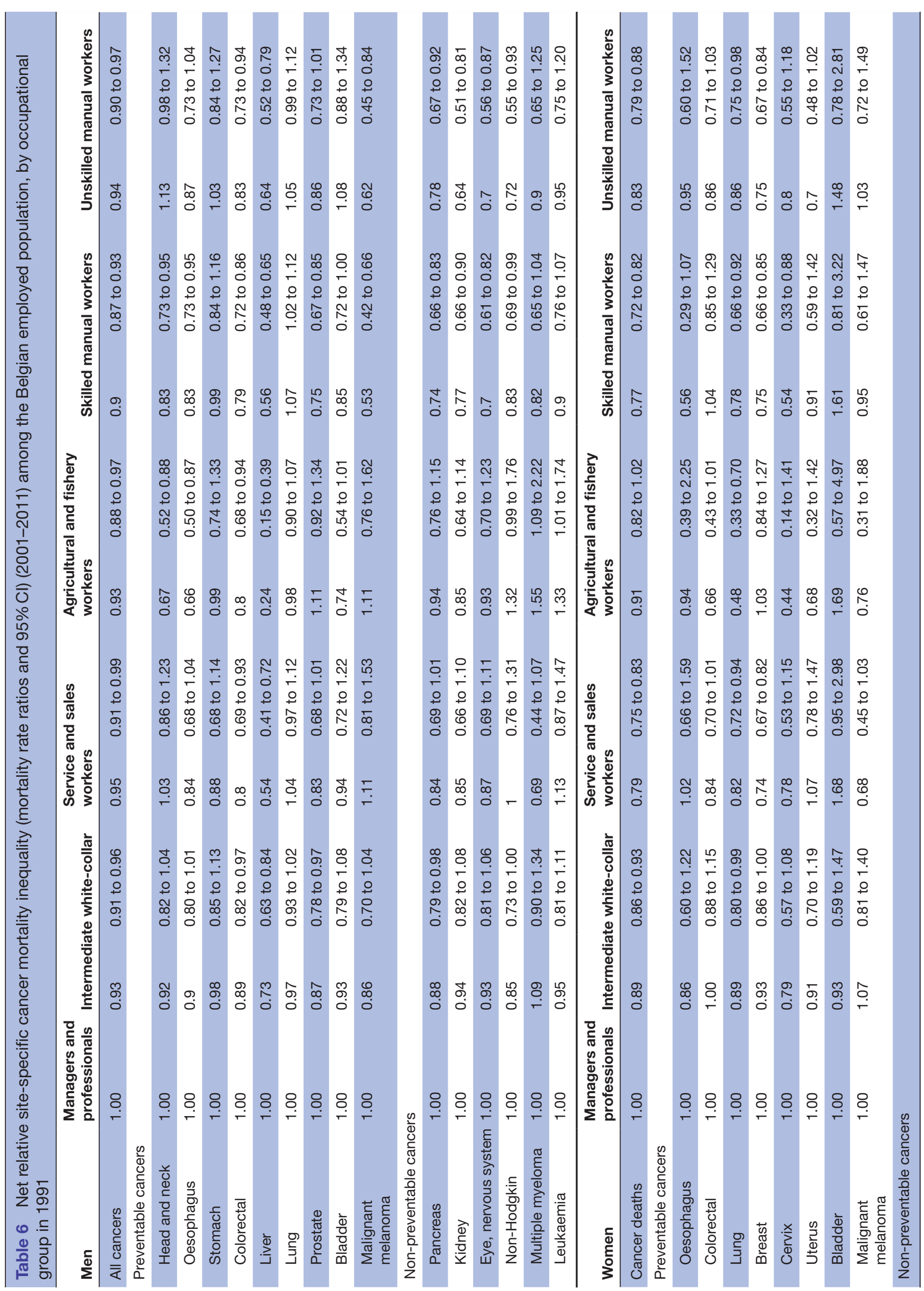




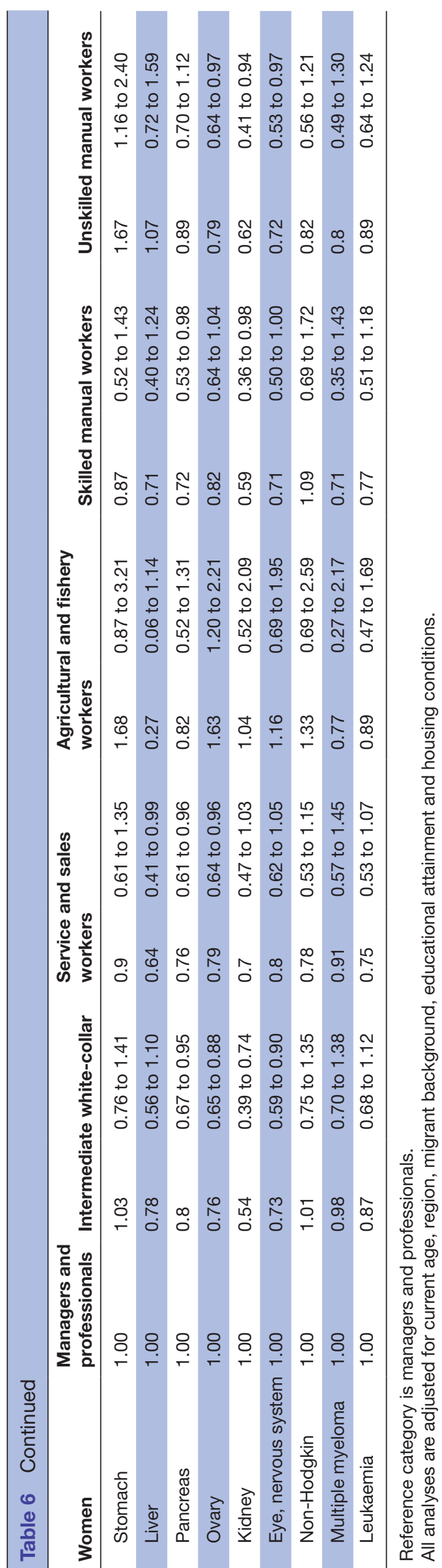

census of 1991, independently of their actual occupational status. We decided so because we were interested in the association between cancer mortality and both employment and occupational group. By doing so, we avoided a selection effect due to including only the healthy workers. ${ }^{625-28}$ Our results indicate the importance of this issue, showing highest (site-specific) cancer mortality among the unemployed groups. Nevertheless, we cannot fully exclude a selection effect among the employed population because we can assume that unhealthy persons are less frequently employed in physically demanding jobs. ${ }^{26}{ }^{27} \mathrm{~A}$ healthy worker effect might then be more likely in the groups of manual workers, which could partly explain some of the observed mortality patterns in favour of manual workers. On the other hand, the whitecollar workers may have less physically demanding jobs, which can counter this effect. Occupational information was derived from the census of 1991, which is the most recent source of detailed information since the census of 2001 does not contain detailed occupational information. Because of the lag time between some (occupational) exposures and cancer mortality, we do not consider this as a problem. ${ }^{29}$ Due to the cross-sectional nature of this information, the occupation is not necessarily the longest job respondents were involved in nor do we have information on the duration of this occupation. ${ }^{25}$ However, occupation was grouped into broad groups, which leads us to assume that the bias due to transitions between occupational categories will be rather small. ${ }^{30}$

We decided not to use the robust distinction between manual versus non-manual workers nor did we focus on one specific cancer site in relation to one or more job exposures. These choices have been made in order to gain insights into the overall association between occupational status and cancer mortality. ${ }^{26}$ Many studies assessing SE inequalities in cancer mortality use only one SE indicator at a time although the importance of including multiple indicators has already been pointed out ${ }^{9} 1112$ because different SEP indicators tap into different pathways. ${ }^{8-10}$ Housing conditions are related to material and financial resources and therefore to healthcare utilisation. ${ }^{31}$ Education captures the human capital acquired early in life and may be related to the ability to adapt health education messages and hence to health behaviours. ${ }^{6}$ Occupational status on the other hand reflects the ability to realise this human capital in the labour market and is rather a reflection of one's social class at older ages. Employment as well as occupation is likely to (partially) capture material resources, access to healthcare as well as social networks and work-related factors such as stress, autonomy and occupational hazards. Hence, we need to analyse all aspects of SEP in relation to health outcomes, although these indicators are closely related. ${ }^{6}$ In this paper, we focus on the net effect of occupational status, thereby adjusting for educational attainment and housing conditions. The results indicate an association between occupational status and site-specific cancer mortality, independently of education and housing conditions. 
Finally, we classified the cancer sites by their level of preventability (see Methods section). We acknowledge that this classification does not exclude the fact that some 'non-preventable' cancers are also related to behavioural change and/or medical interventions nor does it eliminate some possible overlap between these two criteria of preventability. However, to enhance the comparability with other studies, we decided to adopt this often-used classification.

\section{Theoretical considerations on the main findings}

This study reveals inequalities in site-specific cancer mortality by employment and occupational groups. Generally SE inequalities are less pronounced in women compared with men, which is consistent with the literature. $^{7} 2328$ The unemployed group (and especially those not looking for a job) shows both for men and women higher cancer mortality rates compared with the employed, which is in line with previous studies in France and the UK. ${ }^{23}{ }^{32}$ Possible explanations are financial insecurity, which is related to a lower use of healthcare services and an unhealthy lifestyle. ${ }^{32}$ Some studies suggest that part of this association between unemployment and health might be due to health selection, ${ }^{23}$ although others observed an ongoing effect after adjustment for pre-existing morbidity. ${ }^{32}$ However, it is very likely that for the unemployed that are not looking for a job, as well as for the disabled group, health selection will be at play.

Also within the employed group, inequalities by occupational group are observed. In men, these findings are in line with the FCT which expects larger inequalities for more preventable cancer sites. ${ }^{35}$ The absolute results show that male manual workers have the highest site-specific cancer mortality rates whereas white-collar workers and agricultural and fishery workers have the lowest cancer mortality rates. This discrepancy between manual and non-manual workers is in line with previous findings in Europe. ${ }^{63}$ These absolute inequalities are manifest for all preventable cancer sites (except for non-malignant melanoma and prostate cancer), with alcohol-related and smoking-related cancers (eg, cancers of the lung, head and neck and bladder) being the main contributors to these inequalities, as reported in previous studies..$^{252830334}$ The excess mortality for cancers of the head and neck and lung are also observed for male service and sales workers, which can be explained by the higher likelihood of occupational exposure to tobacco and alcohol in bars and restaurants. ${ }^{27}$ Another interesting finding is the favourable cancer mortality pattern for farmers, which might be related to their healthy life style with less tobacco and alcohol use and more physical activity. ${ }^{35} 36$

According to the FCT, the availability of valuable resources such as knowledge, money, power, prestige and beneficial social connections are the social causes of health inequalities. ${ }^{2}$ When there is sound knowledge of the causes and cures of cancers, those in high SEP contexts, with greater access to resources, will disproportionally benefit from this knowledge. Several mechanisms have been suggested to explain this association, such as a differential acquisition of knowledge on health-damaging behaviours (eg, smoking, bad diet, alcohol intake or a lack of exercise).${ }^{6710232637}$ Also, material factors are important: having financial difficulties might be related to poor living conditions ${ }^{723} 30$ or the inability to optimise the use of health services. ${ }^{10} 3337$ Both access to and quality of healthcare are crucial for health outcomes in all stages, from prevention (eg, through cancer screening) to treatment. Finally, the social aspect of SEP is associated with health, for example stress-related factors or the level of social prestige. ${ }^{25}$ Since we cannot adjust for health behaviours or healthcare use, it remains difficult to decide on the extent of inequalities due to each of these mechanisms. ${ }^{26}$ Yet, our findings showed that the inequalities were especially large for the preventable cancer sites related to health behaviours such as smoking and alcohol use. Previous studies indeed reported higher smoking prevalence among manual workers and people working in the catering industry. ${ }^{38}$ However, studies mediating the observed gradients for smoking reported an attenuated but still significant relation between SEP and mortality, ${ }^{72430}$ which assumes that there might be other factors at play as well. Sensitivity analyses not adjusting for education and housing conditions showed both for men and women lowest lung cancer mortality among the managers compared with all other occupational groups (see online Supplementary table 2). However, in the models adjusted for education and housing conditions (presented in table 6), the association reversed for women, whereas for men lung cancer mortality only remains somewhat higher for male skilled manual workers, which could be related to occupational exposures. In contrary, in the adjusted model, higher breast cancer mortality rates were observed in female managers compared with all other occupations except sales and service workers. This can be explained by differences in reproductive behaviour, with less children and a later age at first birth for the whitecollar occupations. ${ }^{24}{ }^{28}$ In the net model, male managers had higher colorectal and liver cancer mortality compared with all other occupations. Yet, in the unadjusted model, the association between occupation and colorectal cancer mortality disappeared (see online supplementary table $2)$. Moreover, compared with the white-collar occupations, manual workers do have lower mortality for several other cancer sites (eg, malignant melanoma and kidney). These results are counterintuitive, suggesting that there are other factors at play, such as an unhealthy and sedentary lifestyle of managers. ${ }^{3940}$

We can assume that the results of the net model are more likely to be due to differences related to the job itself. Yet, a healthy lifestyle may be induced by the social environment (eg, the colleagues at work), and therefore might not be excluded as a potential mechanism. ${ }^{6}$ Specific occupational exposures and hazards may explain part of the association between occupational status and health. ${ }^{71023}$ Another important aspect of work related to health is the psychosocial aspect of the job, such as the 
sense of control and autonomy, the level of job strain or long working hours. ${ }^{723253041}$ This could be an explanation for the excessive colorectal cancer mortality among male managers. Colorectal cancer is associated with perceived stress and could therefore be related to the long working hours and work strain as perceived by managers. ${ }^{39} 41$

\section{Implications and conclusion}

This paper highlights important SE inequalities in site-specific cancer mortality by employment and occupational groups. Being unemployed, and among the employed, being employed as a manual worker or service and sales worker is associated with higher overall and site-specific cancer mortality. These unfavourable mortality patterns among the unemployed and manual and service and sales workers were especially observed for the more preventable cancers, as we assumed based on the FCT. These occupational inequalities change when other SEP indicators are adjusted for. Multiple SEP indicators should be taken into account when studying SE inequalities in health ${ }^{911} 12$ because these allow for different causal pathways. ${ }^{8-10}$ Yet, it is difficult to identify to what extent the potential explanatory factors attribute to these inequalities because we do not dispose of data on incidence or survival, nor on data on risk factors, healthcare use or job characteristics. Future studies having access to these kind of data could help to unravel the complex interplay between incidence, survival and mortality and to clarify at which steps the social differences operate. ${ }^{2324}$

This study can be helpful in providing evidence for policy makers in order to reduce SE inequalities in cancer mortality. ${ }^{37}$ Our results prove that there is still a long way to go. We observed for example that the unemployed groups are at a much higher risk of dying from cancer compared with the employed population. Ensuring financial security for the unemployed is a key issue in this regard. ${ }^{32}$ Future research could also study other working regimes, for example, temporary or part-time employment and their relation to health. Finally, there could be an important role for the general practitioner to make sure that the unemployed are getting the healthcare they need. ${ }^{32}$ Also, for the high-risks jobs, regular health checks at the work floor are needed in order to detect cancers at an early stage.

\section{Acknowledgements The authors would like to thank Didier Willaert for his} indispensable data support.

Contributors KV designed and conducted the study and wrote the first draft of the manuscript. LVdB, HV, PH and SG helped with the interpretation of the results and critically revised this first draft. All authors approved the final version of the manuscript.

Funding This research was funded by the Research Foundation Flanders (Grant number G025813N).

\section{Competing interests None declared.}

Ethics approval This research as well as the data adhere to the ethical code of scientific research in Belgium, and all authors have signed the ethical code.

Provenance and peer review Not commissioned; externally peer reviewed.

Data sharing statement Analyses are based on administrative data from the Belgian census, the Belgian mortality register and death certificates provided by statistics Belgium. The availability of the data is restricted. Permission for analyses must be granted after verification of the research goals by the Belgian commission for the protection of privacy.

Open Access This is an Open Access article distributed in accordance with the Creative Commons Attribution Non Commercial (CC BY-NC 4.0) license, which permits others to distribute, remix, adapt, build upon this work non-commercially, and license their derivative works on different terms, provided the original work is properly cited and the use is non-commercial. See: http://creativecommons.org/ licenses/by-nc/4.0/

(C) Article author(s) (or their employer(s) unless otherwise stated in the text of the article) 2017. All rights reserved. No commercial use is permitted unless otherwise expressly granted.

\section{REFERENCES}

1. Omran AR. The epidemiologic transition: a theory of the epidemiology of population change. 1971. Milbank $Q$ 2005;83:731-57.

2. Phelan JC, Link BG, Tehranifar P. Social conditions as fundamental causes of health inequalities: theory, evidence, and policy implications. J Health Soc Behav 2010;51 Suppl:S28-S40.

3. Phelan JC, Link BG, Diez-Roux A, et al. "Fundamental causes" of social inequalities in mortality: a test of the theory. $J$ Health Soc Behav 2004;45:265-85.

4. Vanthomme K, Vandenheede H, Hagedoorn P, et al. Socioeconomic disparities in lung cancer mortality in Belgian men and women (2001-2011): does it matter who you live with? BMC Public Health 2016;16:493.

5. Rubin MS, Clouston S, Link BG. A fundamental cause approach to the study of disparities in lung cancer and pancreatic cancer mortality in the United States. Soc Sci Med 2014;100:54-61.

6. Toch-Marquardt M, Menvielle G, Eikemo TA, et al. Occupational class inequalities in all-cause and cause-specific mortality among middleaged men in 14 European populations during the early 2000s. PLoS One 2014;9:e108072.

7. McFadden E, Luben R, Wareham N, et al. Occupational social class, educational level, smoking and body mass index, and cause-specific mortality in men and women: a prospective study in the European Prospective Investigation of Cancer and Nutrition in Norfolk (EPICNorfolk) cohort. Eur J Epidemiol 2008;23:511-22.

8. Naess O, Claussen B, Thelle DS, et al. Four indicators of socioeconomic position: relative ranking across causes of death. Scand J Public Health 2005;33:215-21.

9. Geyer S, Hemström O, Peter R, et al. Education, income, and occupational class cannot be used interchangeably in social epidemiology. Empirical evidence against a common practice. $J$ Epidemiol Community Health 2006;60:804-10.

10. Davey Smith G, Hart C, Hole D, et al. Education and occupational social class: which is the more important indicator of mortality risk? J Epidemiol Community Health 1998;52:153-60.

11. Geyer S. Social inequalities in the incidence and case fatality of cancers of the lung, the stomach, the bowels, and the breast. Cancer Causes Control 2008;19:965-74.

12. Krieger N, Williams DR, Moss NE. Measuring social class in US public health research: concepts, methodologies, and guidelines. Annu Rev Public Health 1997;18:341-78.

13. Van Oyen $\mathrm{H}$, Berger $\mathrm{N}$, Nusselder W, et al. The effect of smoking on the duration of life with and without disability, Belgium 1997-2011. BMC Public Health 2014;14:723.

14. Mackenbach JP, Kulhánová I, Bopp M, et al. Variations in the relation between education and cause-specific mortality in 19 European populations: a test of the "fundamental causes" theory of social inequalities in health. Soc Sci Med 2015;127:51-62.

15. Ezzati M, Vander Hoorn S, Lopez A, et al. Chapter 4. Comparative quantification of mortality and burden of disease attributable to selected risk factors. In: Lopez A, Mathers C, Ezzati M, eds. Global burden of disease and risk factors. Washington (DC: World Bank, 2006:241-68.

16. EUROCARE-5 Working Group. EUROCARE-5 on-line database. 2014 https://w3.iss.it/site/EU5Results/forms/SA0007.aspx (accessed 1 Dec 2015).

17. Vrijens F, Renard F, Camberlin C, et al. Performance of the Belgian health system - report 2015. Brussels: supplement health Services Research (HSR), 2016.

18. ILO. The revised international standard classification of occupations(ISCO-88, 1990. 
19. Vandenbroucke JP, von Elm E, Altman DG, et al. Strengthening the Reporting of Observational Studies in Epidemiology (STROBE): explanation and elaboration. PLoS Med 2007;4:e297.

20. Deboosere P, Willaert D. Codebook Algemene Socio-economische enquête 2001. Brussel, 2004.

21. Humblet PC, Lagasse R, Levêque A. Trends in Belgian premature avoidable deaths over a 20 year period. J Epidemiol Community Health 2000;54:687-91.

22. De Grande H, Vandenheede H, Gadeyne S, et al. Health status and mortality rates of adolescents and young adults in the BrusselsCapital Region: differences according to region of origin and migration history. Ethn Health 2013:1-22.

23. Saurel-Cubizolles MJ, Chastang JF, Menvielle G, et al. EDISC group. Social inequalities in mortality by cause among men and women in France. J Epidemiol Community Health 2009;63:197-202.

24. Steenland K, Hu S, Walker J. All-cause and cause-specific mortality by socioeconomic status among employed persons in 27 US states, 1984-1997. Am J Public Health 2004;94:1037-42.

25. Christ SL, Fleming LE, Lee DJ, et al. The effects of a psychosocial dimension of socioeconomic position on survival: occupational prestige and mortality among US working adults. Sociol Health IIIn 2012;34:1103-17.

26. Alexopoulos EC, Messolora F, Tanagra D. Comparative mortality ratios of cancer among men in Greece across broad occupational groups. Int Arch Occup Environ Health 2011;84:943-9.

27. Coggon D, Harris EC, Brown T, et al. Work-related mortality in England and Wales, 1979-2000. Occup Environ Med 2010;67:816-22.

28. Borrell C, Cortès I, Artazcoz L, et al. Social inequalities in mortality in a retrospective cohort of civil servants in Barcelona. Int $J$ Epidemiol 2003:32:386-9.

29. Van den Borre L, Deboosere P. Enduring health effects of asbestos use in Belgian industries: a record-linked cohort study of causespecific mortality (2001-2009). BMJ Open 2015;5:e007384.
30. Regidor E, Ronda E, Martínez D, et al. Occupational social class and mortality in a population of men economically active: the contribution of education and employment situation. Eur J Epidemiol 2005;20:501-8

31. Merletti F, Galassi C, Spadea T. The socioeconomic determinants of cancer. Environ Health 2011;10(Suppl 1):S7.

32. Wilson SH, Walker GM. Unemployment and health: a review. Public Health 1993;107:153-62.

33. Rosengren A, Wilhelmsen L. Cancer incidence, mortality from cancer and survival in men of different occupational classes. Eur J Epidemiol 2004;19:533-40.

34. McCartney G, Russ TC, Walsh D, et al. Explaining the excess mortality in Scotland compared with England: pooling of 18 cohort studies. J Epidemiol Community Health 2015;69:20-7.

35. Blair A, Sandler DP, Tarone R, et al. Mortality among participants in the agricultural health study. Ann Epidemiol 2005;15:279-85.

36. Acquavella J, Olsen G, Cole P, et al. Cancer among farmers: a metaanalysis. Ann Epidemiol 1998;8:64-74.

37. Ramsay SE, Morris RW, Whincup PH, et al. Time trends in socioeconomic inequalities in cancer mortality: results from a 35 year prospective study in British men. BMC Cancer 2014;14:474

38. Centers for Disease Control and Prevention. Current cigarette smoking prevalence among working adults - United States, 2004-2010 cigarette. Morb Mortal Wkly Rep 2011;60:1305-9.

39. Wada K, Gilmour S. Inequality in mortality by occupation related to economic crisis from 1980 to 2010 among working-age Japanese males. Sci Rep 2016;6:22255.

40. Stamatakis E, Chau JY, Pedisic Z, et al. Are sitting occupations associated with increased all-cause, cancer, and cardiovascular disease mortality risk? A pooled analysis of seven British population cohorts. PLoS One 2013;8:e73753.

41. Kojima M, Wakai K, Tokudome S, et al. Perceived psychologic stress and colorectal cancer mortality: findings from the Japan Collaborative Cohort Study. Psychosom Med 2005;67:72-7. 